\title{
Self-education and self-management to develop entrepreneurship compe- tence in future professionals
}

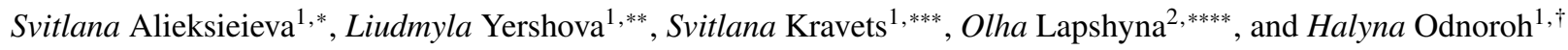 \\ ${ }^{1}$ Institute of Vocational Education and Training of the NAES of Ukraine, 98-a Vito-Litovsky Ln., Kyiv, 03045, Ukraine \\ ${ }^{2}$ Khmelnystkyi National University, 11 Instytutska Str., Khmelnytskyi, 29016, Ukraine
}

\begin{abstract}
The relevance of this article lies in the need to improve the process of developing competences future professionals need to develop self-employment skills under the conditions of the socio-economic crisis and the instability of the Ukrainian labour market. The article aims to prove the need for systematic implementation of self-education and self-management technologies in Ukrainian professional education schools to develop entrepreneurship competence in future professionals. Research methods include a survey and an analysis of documentary information. Ukraine strives to increase the importance of young people's readiness for lifelong learning. However, the article finds that most students do not have sufficient psychological knowledge and selfmanagement skills for successful self-development and self-employment. The development of entrepreneurship competence is, for the first time, justified through the systemic implementation of self-education and selfmanagement technologies in the educational process of professional education schools. The article presents a pedagogical technology for developing entrepreneurship competence in future professionals through selfmanagement. Besides, it offers the most effective forms of its introduction (psychology workshops, video lectures, electronic portfolios) and singles out the optimal conditions of their use. The level of the technology's readiness is IRL5 (the efficiency was proven at the level of experimental educational institutions). Success in its implementation depends on the regulatory recognition of the role of the social and humanities-related component in professional education; the incorporation of a self-management course in all programmes for training, retraining and advanced training of psychology and teaching staff; the encouragement of teaching staff to effectively use the described technologies in the educational process; systematic training of students to implement self-education and self-management as the technologies of success.
\end{abstract}

\section{Introduction}

The experience of the advanced countries shows that entrepreneurship today is the most innovative system of economic management regardless of the socio-economic structure of society. The proceedings of the World Economic Forum, analytical reports of the USAID Leadership in Economic Governance Program, UNDP Programme and other statistical materials highlight the importance of entrepreneurship for the world and national economies. The features of modern entrepreneurship include the optimization of the profitability potential, the use of creative approaches to business organization, the search for new resources, innovation, optionality, innovation and social responsibility.

The development of entrepreneurial activity is one of the main prerequisites for developing and realizing the state's potential since entrepreneurs form a significant part of the tax revenues of the state and local budgets. Given the socio-economic crisis and instability of the labour mar-

\footnotetext{
*e-mail: svetlanav@i.ua

**e-mail: yershova67@ukr.net

***e-mail: sveta.kindz@ukr.net

****e-mail: olga1807komochkova@gmail.com

†e-mail: rgv.20.04@gmail.com
}

ket today, entrepreneurship may be the beginning of a business career for young professionals and an opportunity for creativity, professional self-realization and success. Entrepreneurial activity of today's youth should provide the appropriate economic and social effect. The latter should lie in improving living standards, reducing unemployment rates and creating new jobs. Moreover, it should contribute to building the middle class, which will serve as the basis of socio-economic reforms and the guarantor of political and social stability of a democratic society.

The United Nations has identified three global goals for education to contribute to the issue under consideration. They are as follows: to improve employment through involvement in entrepreneurship and, thus, contribute to sustainable economic development; to strengthen social integration; to involve future professionals in community activities; to provide access to lifelong learning.

On January 17, 2018, the European Parliament and the Council of the European Union approved the Revised Key Competences for Lifelong Learning Framework. It defines entrepreneurship competence as a key competence that will promote financial literacy, social integration, active citizenship, equality and democracy [1]. 
The global pandemic has also become a challenge for all spheres of human life [2-5]. It has highlighted the issue of adjusting professional training to the needs of the post-pandemic labour market. The paradigm shift of economic and social relations, as a result of the long quarantine, has motivated students to acquire those competences that will promote professional mobility, self-development, self-improvement and self-employment [6].

Entrepreneurship competence will become a tool for solving many important economic and social issues. They mostly involve providing the national market with various goods, reducing unemployment rates, building the middle class, enhancing competition, cultivating economic culture and many others.

Many documents address the need to develop entrepreneurship competence in future specialists. These documents include the Copenhagen Declaration, the Bruges Communique, the Laws of Ukraine "On Vocational Education", "On Education", "On Development and State Support of Small and Medium-Sized Businesses in Ukraine", the National Doctrine of Education Development in Ukraine in the 21st Century, the Strategy for Small and Medium-Sized Enterprise Development in Ukraine until 2020, the National Strategy for Education Development in Ukraine for 2012-2021, the National Programme for Small Business Development in Ukraine, the Government's Medium-Term Priority Action Plan for the period up to 2020, the Concept of the New Ukrainian School.

In the context of this research, noteworth are foreign studies in which the efficiency of entrepreneurship is inextricably linked with the quality of human capital [7-9], the main attention is focused on the importance of developing creativity in future entrepreneurs [10], heuristics and activity $[7,11]$, as well personal qualities one needs for selfdevelopment [11-13]. Researchers highlight the relevance of developing the cognitive component of entrepreneurship competence [14], psychological, economic and legal readiness for entrepreneurship [15-17], digital competence [18-30], as well as using crowd technologies [18] and boosting motivation towards self-improvement [20]. It is important to note that only Ukrainian researchers focus on the economic and legal aspects of preparing young people for entrepreneurship. World class researches usually presents the issues of self-education and self-management through proving the effectiveness of investment in human capital for business success.

In 2019, the employees of the professional career laboratory at the Institute of VET of the NAES of Ukraine conducted a survey [31] to study the readiness of future skilled workers for entrepreneurship. The survey involved 658 respondents, namely, students from Higher Vocational School No 11 (Khmelnytskyi), Vinnytsia Vocational Education Centre for Processing Industry (Vinnytsia), Lviv Higher Vocational Arts School (Lviv), Odesa Higher Vocational School of Trade and Food Technology (Odesa), Regional Vocational Education Centre for Garment Production and Service Sector of Kharkiv Oblast (Kharkiv), Cherkasy Professional Road-Transport Lyceum (Cherkasy). The analysis of documentary information helped to study relevant scientific sources on the issues of developing entrepreneurship competence, self-education and self-management.

The article aims to prove the need for systematic introduction of self-education and self-management technologies in professional (vocational) education $(\mathrm{P}(\mathrm{V}) \mathrm{E})$ schools based on the analysis of relevant scientific sources and results from students' assessment of their readiness for entrepreneurial activity.

\section{Results and discussion}

According to the EU Framework Programme, entrepreneurship is the ability to respond to opportunities, ideas and turn them into values [1]. Entrepreneurship is considered as an independent, systematic production of goods, performance of works, provision of services by individuals and legal entities registered as business entities to receive income in the manner prescribed by law (Art 1 of the Law of Ukraine "On Entrepreneurship") [32]. Entrepreneurship as the most flexible form of production organization responds quickly to market needs, as well as to the latest advances in scientific progress. Also, it promotes timely structural changes in the economy. The development of entrepreneurs means the development of young carriers of innovative ideas and projects, authors of extraordinary techniques and technologies, inventors of new ways and means of social development.

Entrepreneurship competence implies certain knowledge, skills and attitudes towards the use of entrepreneurial approaches to solving social problems and introducing innovations. The basic knowledge, skills, abilities and qualities related to entrepreneurship competence include [1]:

a) knowledge about ways of turning ideas into personal, social and professional activities, approaches to project planning and management, understanding of economic and social opportunities and ethical principles,

b) such skills as creativity, strategic thinking, critical analysis of creative processes and innovations, independent financial decision-making regarding price and value, effective communication and negotiation, emotion management, reasonable decision-making,

c) qualities characterizing entrepreneurship (initiative, activity, curiosity, courage and perseverance in achieving goals, desire to motivate others and value their ideas, empathize and care about people and the world, take responsibility for the ethics of actions throughout the process).

The strategic goal of modern education is to create a highly educated, intellectual, self-sufficient and creative person with an innovative type of thinking and activity who can respond to today's challenges adequately. The existing socio-economic conditions and competition in the labour market require future professionals to understand the basics of entrepreneurship. This issue is especially relevant under globalization of economic processes, given the increasing socio-economic importance of entrepreneurship. 
The results of the survey show that modern young people actively perceive entrepreneurial values and attitudes. Indeed, the vast majority of respondents are at a high level of professional motivation and are ready to take responsibility for their professional future. Besides, 541 students $(82.22 \%)$ express their readiness to develop themselves in the chosen field and build a professional career. At the same time, only $19.15 \%$ of respondents indicate that they plan to start their own business in the chosen field; 6.53\% of them are ready to work as entrepreneurs in another field [14]. The conducted surveys show the need to enhance the theoretical and practical training of students for entrepreneurship. First of all, it should motivate them to be able to run their own business. Next, such training should provide a holistic vision of the essence and content of business activities, promote the development of entrepreneurial thinking and develop the ability to implement the acquired knowledge in practice.

Still, the analysis of educational practice shows certain issues hindering these processes. Despite some positive changes, reinforcement and promotion of entrepreneurship in Ukraine, there are insufficient conditions for preparing young people for entrepreneurship. Educational institutions employ outdated approaches to learning and do not take into account modern trends in innovative and social entrepreneurship. One can solve these issues by developing and implementing innovative measures in educational activities. They will be able to maximize the reserve capacity of consciousness, psyche, thinking and help to involve young people in entrepreneurship within the educational process. It mainly concerns the active use of online learning resources and self-management technologies.

Today, there are many online learning resources, which prepare for entrepreneurship. The use of Internet resources contributes to flexibility, accessibility, expansion and modernization of training future professionals for entrepreneurship. It helps to specify methods and tools, facilitate independent activities and individualize the educational process, taking into account the needs of young people. Such online resources include courses for creating startups and opening one's social and innovative business.

The well-known online learning resource is the Prometheus platform [33], which offers an online course, titled "Entrepreneurship. One's Business in Ukraine". It offers video lectures on preparation for entrepreneurship and covers the success stories of young entrepreneurs, analyzes their mistakes and provides recommendations. In particular, the platform shows the experience of such startupers as Nataliia Misnyk (Be My Guest Bakery), Andrii Peliukhovskyi (Smart Coffee), Yaroslav Kaplan (Escape Quest), Lydiia Suiarko (UA Krasa), Oksant Tymkiv (ABC Club Children's Development Centres), Yuliia Savostina (Made in Ukraine Festival). As noted by the developers, this course provides not only knowledge but also strength and inspiration to take responsibility, show initiative and change reality. The Prometheus offers a series of courses based on innovative techniques. The course, titled "Introduction to the Theory of Constraints" reveals the methodology of company management, which differs significantly from the existing one. This course helps par- ticipants to understand the theory of constraints and traditional methods of company management. It pays particular attention to pragmatic tools of constraint theory, in particular thought processes.

Modern online forms for preparing young people for entrepreneurship include educational series, in particular the educational series "Start a Startup" available on the Ukrainian platform "Diia. Tsyfrova Osvita" (Action. Digital Education) [34]. It covers the key issues in creating startups.

It is also essential to use the National Platform for Small and Medium-Sized Business as educational content in the preparation of future professionals for entrepreneurship [35]. It contains materials for self-education, in particular, "A Useful Textbook on Creative Entrepreneurship" [36]. This resource presents methods for developing, testing and transforming creative ideas into a real business, which will help one to plan, build and develop a new creative business. Besides, it offers the PRO platform for effective regulation [37], which includes step-by-step instructions for starting a business and interacting with the authorities.

Only a person who has learned how to manage and understand oneself can start one's own business and manage others. Therefore, it is of paramount importance to teach one to know oneself. However, it is almost impossible to manage oneself, one's time, life and activity, engage in self-development and self-improvement without self-management [38].

Personal management implies developing clear algorithms for time-management and self-development to achieve personal and professional success based on rational selection of appropriate methods, techniques and forms of teaching influence. Thus, the goal of selfmanagement technologies is to teach future professionals to achieve personal and professional success. The main objectives of these technologies are the following: to optimize time expenditure; to use intellectual, physical and emotional resources rationally; to increase productivity. The main areas of self-management are time management, personal management, life management.

Time management is a set of methods and techniques for flexible organization of time to perform current tasks and projects. Nowadays, time management is most often called "a technology" since it offers clear algorithms for achieving well-defined results (streamlining work $\rightarrow$ saving time $\rightarrow$ increasing productivity $\rightarrow$ quality and timely results). Typical approaches to time management involve setting priorities, breaking down large tasks and projects into individual actions and delegating individual tasks to others. Time management also includes methods of influencing motivation and monitoring results. The main support tools of time management are a personal calendar, a list of current tasks and a list of projects. Time management mechanisms (calendar and to-do list, their categorization and prioritization) are also implemented in various softwares (Microsoft Outlook, iCal) and smartphones, PDAs. Psychological training sessions are more and more focused on the issues of time management and its techniques. The most popular time management tech- 
niques are "The Eisenhower Matrix", "The Pomodoro Technique", "The Pareto Principle", "The ABC Analysis", "The Eat the Frog Technique" and others.

Personal management is a way of managing one's personality and career development and achieving certain goals, as well as an individual technology of effective use of personal time-space. The simplest model of personal management [39] includes several of the most important interrelated functions. They involve setting, analyzing and creating personal goals; planning and elaborating alternatives; making decisions; realizing and organizing self-development, compiling to-do lists, organizing one's work; enabling information and communication; correcting goals; self-motivation and self-control. The model also helps one to develop some important personal qualities. They include the following: self-knowledge (ability to determine one's inclinations, weaknesses and strengths, creativity, characteristics of perception, temperament, character, emotional and volitional sphere, communication); ability to formulate one's life goals and values (knowledge about moral and ethical principles; readiness to build a hierarchy of personal, career, civic and other values and define personal and career goals); decision-making (ability to set priorities, make optimal choices, act rationally, avoid overload); self-organization (ability to organize personal time-space rationally, use one's internal resources effectively and take care of mental and physical health); self-discipline (self-control, self-regulation, integrity, punctuality); career planning (ability to make career plans and determine professional tasks and deadlines); self-improvement (ability to create a strategy for personal development, use self-cultivation techniques and technologies, develop the skills needed to achieve personal and professional success).

Life management is the way one lives one's life. In ancient times, a person was seen as an adjunct to large social groups (the state, nation, class, social class) which determined and exercised external control over the lives of each of its members. The power of the group was exercised regardless of the desires and aspirations of people. Besides, it was consolidated by the power of tradition, custom, law and morality of the time. In modern democratic society, a person is the leader and organizer of his or her life. Democracy condemns external management of human destiny, creating conditions for comprehensive development of human talents and abilities and effective selfrealization in the family, profession, society. The concept of life management, voluntary and conscious management of one's destiny, has become the embodiment of independence and responsibility for one's life.

Nowadays, different scientific sources often identify the concepts of personal management and life management as the same ones. However, there are serious differences between them. Indeed, life management is strategic management, while personal management, time management and other areas of self-regulation act as tools which contribute to effective implementation of strategic life plans.

It is essential to teach future professionals to build the right strategic scheme of personal and career development; to familiarize them with the mechanisms of rapid response to socio-economic, political and cultural transformations; to develop their memory, thinking, creative skills and sociability; to strengthen their volition; to motivate them to manage their psycho-emotional states, generalize and integrate life experience. All this is possible only through selfobservation, self-analysis, self-control, self-regulation and self-improvement. A person's life success directly depends on the level of these qualities.

Importantly, the results of the survey on $\mathrm{P}(\mathrm{V}) \mathrm{E}$ schools students' readiness to run an independent business show that $82 \%$ of them consider themselves ready for it. However, the vast majority of respondents in each educational institution acknowledge the lack of necessary resources, knowledge and experience. More than $20 \%$ of the surveyed students feel the lack of psychological knowledge about personal skills they need to open and run a business. At the same time, $52 \%$ of them are either completely unfamiliar with psychological traits and qualities necessary for entrepreneurship or have never done any psychological tests and do not know how they are expressed in them. Almost $16 \%$ of respondents admit that they do not have self-presentation skills; $27 \%$ of them believe that they do not know how to present their business idea; $15 \%$ of them do not know how to use popular social networks for self-presentation, labour market analysis and promotion of their business ideas.

Thus, $\mathrm{P}(\mathrm{V}) \mathrm{E}$ schools need to familiarize future professionals with the basics of self-management and provide them with the necessary psychological knowledge for successful entrepreneurship. In this regard, one should introduce a pedagogical technology for developing entrepreneurship competence in future professionals using some elements of self-management. It is a system of stepby-step pedagogical actions regarding training, education and development focused on self-management forms, methods and techniques to cultivate the qualities, abilities and skills one needs to open a successful business. The main result of this technology lies in a set of personal qualities which underlie the main components of entrepreneurship competence. They include self-awareness, personal values, self-motivation, self-knowledge, labour market, entrepreneurial activity, level of aspirations and self-esteem, self-improvement, self-actualization and selfpresentation. However, one needs to use psychology workshops, video lectures and electronic portfolios to implement this technology.

A psychology workshop is a set of both offline and online diagnostic and counselling procedures conducted by psychologists, social educators, class supervisors, invited professionals under the approved programme on psychological diagnostics and counselling at the career centre of the educational institution (if any). These procedures aim to inform students about the traits they need to develop professional competence, teach them to determine peculiarities of their temperament, character, emotions, communication and make a self-portrait. Besides, they help students to identify traits and qualities favourable and unfavourable for developing entrepreneurship competence and build a strategy for personal development and profes- 
sional career. To do this, psychologists, social educators or class supervisors select the techniques necessary for psychological diagnostics of students. Before each test, they should acquaint students with some psychological phenomenon that they will explore later. Tests can be done individually online or in small groups in optional lessons or during group consultations, homeroom hours in compliance with the necessary conditions for this type of work. After completing tests, each student needs to determine his or her development level of the phenomenon under study and record the results in a special copybook (if technically possible, one can create an interactive online copybook). The findings of the tests included in the testing programme serve as the basis for making a self-portrait, which should reveal the traits and qualities favourable and unfavourable for running one's own business. Next, students need to create a strategy of self-realization [17], in which they determine the trajectory of their professional career and the stages of their business development.

A video lecture is organized screening and discussion of documentaries and feature films on entrepreneurship. It is a very effective form of developing personal traits important for starting and running a business. It acquaints students with real and invented images of successful entrepreneurs, analyzes specific situations of success, struggle for one's ideals and values and shows ways to overcome difficulties and be socially responsible. Showing the stories of real successful business projects, video lectures stimulate students' interest in entrepreneurship. Besides, they are convenient to work in the classroom, during extracurricular activities or remotely. They can be used during the holidays, without distracting students from classroom activities and preparation for them. Importantly, teachers should prepare a list of questions students need to answer after watching each film to increase the pedagogical effectiveness of video lectures. After watching, teachers and students can discuss such films during homeroom hours, in lessons of certain subjects, on social networks or through Microsoft Teams, Zoom, Skype. The best forms for discussion involve writing essays.

An electronic portfolio is an electronic resource for storing and disseminating information about the achievements of future professionals of a particular educational institution. It aims to record and accumulate their achievements, professional growth and results during their studies at the educational institution. This is a very promising way to develop such important business qualities as self-motivation, self-esteem, self-improvement, selfactualization and self-presentation. When working on the content of the electronic portfolio, students develop selfassessment, self-motivation, self-development and selfimprovement skills. Electronic portfolios contain information about students' abilities, values, plans, achievements, honours and awards in the main areas of their lives. These are as follows: personal ("the self-personality" - the most promising personality traits and qualities important for personal and professional success and social recognition); family-related ("the self-family" - the most important family and family values, traditions, plans); social ("the self-citizen" - socially responsible skills, civic competences, volunteering experience); professional ("the self-professional" - professional goals and values, examples of professional activity, workshops, skill presentations). Electronic portfolios can be created on the website of the educational institution as separate personal pages. The information they contain may include hyperlinks to many documents stored in cloud services or on the pages of other websites. Thus, information about the student's progress becomes available to the general public and may be of interest to potential employers while still in school. At the same time, such portfolios have a fairly wide range of practical implementation depending on technical facilities in the educational institution and teachers' and students' ICT competences.

Using the described forms of work to develop entrepreneurship competence in future professionals opens special opportunities for establishing strong interdisciplinary links. In particular, the process of making a psychological self-portrait can combine the efforts and experience of psychologists, social workers, class supervisors and subject (history, language and literature) teachers. Class supervisors or social educators organize testing; psychologists conduct individual consultations on its results; language teachers help students to make a psychological self-portrait as a discursive essay on their traits, qualities and development prospects. Also, such portfolios contribute to developing digital skills $[19,20,40]$ and unite computer science teachers (administering the educational institution's website, creating a local network of private portfolios, teaching students to upload content to their pages, preparing presentations, editing movies), psychologists and class supervisors (teaching students to create an archive of their successes and achievements, defining tasks for self-development and self-improvement, developing self-presentation skills), vocational masters, methodologists and educators (teaching to systematically record and effectively present the results of students' professional activities during industrial practice).

Thus, it is possible to organize thought-provoking and effective work in the educational institution to prepare students for entrepreneurship using the self-management technology, even during the quarantine, as long as teachers are well-trained, motivated and eager to work together.

A certain system has been developed to assess students' initial knowledge, skills and learning outcomes to develop entrepreneurship competence in future professionals in $\mathrm{P}(\mathrm{V}) \mathrm{E}$ schools. It covers the diversity of entrepreneurship competence, criteria and indicators for assessing it. In the first year of the experiment, the introduction of this system in the experimental institutions has shown significant changes in students ability to conduct a cost analysis and marketing research, calculate certain taxes, develop business plans, present and defend entrepreneurial ideas.

The authors of the article have used the materials of the experiment conducted by the professional career laboratory at the Institute of VET of the NAES of Ukraine on the development of entrepreneurship competence in students from $\mathrm{P}(\mathrm{V}) \mathrm{E}$ schools to prove the effectiveness of the above mentioned technologies. The experimental (EG) and con- 


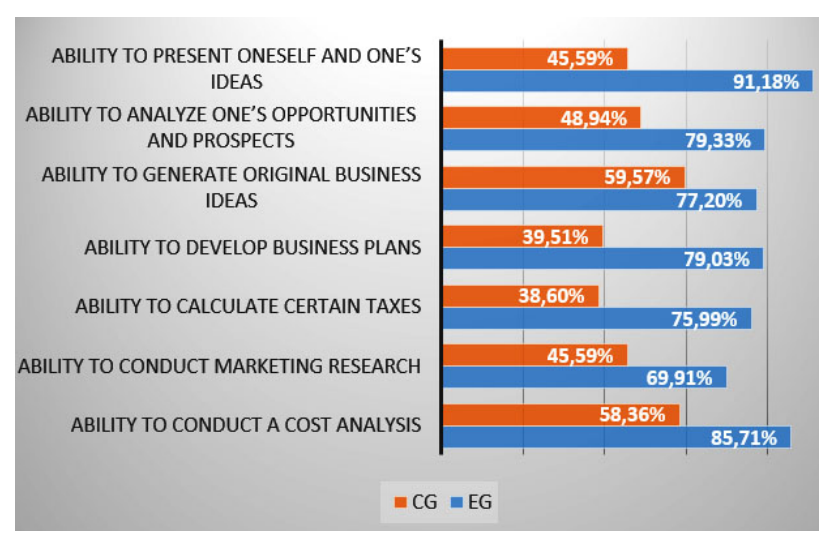

Figure 1. The dynamics of entrepreneurship competence development

trol (CG) groups, having 329 respondents each, were identified as part of the experiment. It is important to note that CGs followed traditional methods, while EGs used the above-mentioned technologies (self-education with the use of online learning resources and self-management) (see figure 1).

Students were offered to match certain concepts and definitions and solve certain problems. It was necessary to check their understanding of the main economic categories, entrepreneurial management mechanisms, provide them with the necessary psychological knowledge and develop their self-management skills. The assessment of students' knowledge and skills has made it possible to determine the dynamics of positive changes in the development of entrepreneurship competence (cognitive and personality-reflexive components).

Thus, the obtained results allow one to recognize the proposed measures as effective.

\section{Conclusions}

This article considers the development of entrepreneurship competence, as its initial category, in two aspects. They involve the contexts of self-education (independent acquisition of knowledge, skills and abilities necessary for successful entrepreneurship) and self-management (willingness for self-realization, self-development and selfaffirmation through entrepreneurial initiative). The analysis of relevant scientific sources and collected empirical data proves that the development of entrepreneurship competence should be based on one's readiness for lifelong learning. The article shows that the informational and psychological components of self-education should become the active use of online learning resources and self-management technologies. Today, they are the most effective way to develop a system of knowledge, skills, views, beliefs and qualities one needs to open a successful social or innovative business.

The importance of one's psychological readiness to run a business and ability to use emotional, physical, intellectual, time and material resources rationally is obvious. Yet, the authors of the article have experimentally proved that most students do not have sufficient psychological knowledge or self-management skills. Besides, they have introduced the pedagogical technology for developing entrepreneurship competence in future professionals using self-management, as well as the most effective forms of its introduction (psychology workshops, video lectures, electronic portfolios). They claim that teacher education should prepare teachers for the effective use of the described technologies in the educational process. Importantly, all programmes for training, retraining and advanced training of psychology and teaching staff should include a self-management course. One of the key objectives of social and humanities-related education in $\mathrm{P}(\mathrm{V}) \mathrm{E}$ schools should be to prepare young people for the implementation of self-management as a technology of success.

In this regard, future research should aim to design and verify innovative teaching forms and methods aimed at enhancing the development of entrepreneurship competence in future professionals in $\mathrm{P}(\mathrm{V}) \mathrm{E}$ schools using selfeducation and self-management.

\section{References}

[1] European Commission, Proposal for a council recommendation on key competences for life-long learning (2018), https://eur-lex. europa.eu/resource.html?uri=cellar: 395443f6-fb6d-11e7-b8f5-01aa75ed71a1. $0001.02 / D 0 C \_1 \&$ format=PDF

[2] O. Burov, A. Kiv, S. Semerikov, A. Striuk, M. Striuk, L. Kolgatina, I. Oliinyk, CEUR Workshop Proceedings 2731, 1 (2020)

[3] A. Kiv, P. Hryhoruk, I. Khvostina, V. Solovieva, V. Soloviev, S. Semerikov, CEUR Workshop Proceedings 2713, 1 (2020)

[4] M. Velykodna, Psychodynamic Practice 27, 10 (2021)

[5] V.N. Soloviev, A.O. Bielinskyi, N.A. Kharadzjan, CEUR Workshop Proceedings 2832, 24 (2020)

[6] L. Yershova, Professional Pedagogics 1, 151-159 (2020)

[7] M.A. Hitt, L. Bierman, K. Shimizu, R. Kochhar, Academy of Management Journal 44, 13 (2001)

[8] O. Kuzmin, M. Bublyk, A. Shakhno, O. Korolenko, H. Lashkun, E3S Web of Conferences 166 (2020)

[9] Y. Makazan, V. Los, E3S Web of Conferences 166 (2020)

[10] G. Ahuja, C. Lampert, Strat. Man. J. 6, 521 (2001)

[11] T.R. Holcomb, R.D. Ireland, J. R. Michael Holmes, M.A. Hitt, Entrepreneurship Theory and Practice 33, 167 (2009)

[12] E. Chell, The entrepreneurial personality: a social construction, 2nd edn. (Routledge, London, 2008)

[13] A.C. Corbett, K.M. Hmieleski, Entrepreneurship Theory and Practice 31, 103 (2007)

[14] S. Alekseeva, H. Sokhatska, Professional Pedagogics 1, 127-133 (2020) 
[15] B. Dratver, D. Zakatnov, V. Machuskyi, N. Pasichnyk, Osnovy pidpryiemnytskoi diialnosti (Imeks, Kirovohrad, 2003)

[16] M. Tkachenko, Professional Pedagogics 14, 93 (2017)

[17] V. Loznytsia, The Psychology of Management. Theory and Practice (EksOb, Kyiv, 2001)

[18] L.M. Petrenko, V.P. Shevchenko, O.O. Zelikovska, Information Technologies and Learning Tools 76, 213 (2020)

[19] H.I. Ivaniuk, L.V. Kuzemko, I.M. Novyk, Information Technologies and Learning Tools 79, 73 (2020)

[20] L. Petrenko, I. Varava, A. Pikilnyak, CEUR Workshop Proceedings 2643, 626 (2020)

[21] O. Kuzminska, M. Mazorchuk, N. Morze, V. Pavlenko, A. Prokhorov, CEUR Workshop Proceedings 2104, 366 (2018)

[22] N. Balyk, Y. Vasylenko, G. Shmyger, V. Oleksiuk, A. Skaskiv, CEUR Workshop Proceedings 2393, 204 (2019)

[23] Y. Nosenko, A. Sukhikh, CEUR Workshop Proceedings 2393, 178 (2019)

[24] A. Iatsyshyn, V. Kovach, Y. Romanenko, A. Iatsyshyn, CEUR Workshop Proceedings 2433, 197 (2019)

[25] M. Moiseienko, N. Moiseienko, I. Kohut, A. Kiv, CEUR Workshop Proceedings 2643, 60 (2020)

[26] O. Prokhorov, V. Lisovichenko, M. Mazorchuk, O. Kuzminska, CEUR Workshop Proceedings 2731, $312(2020)$

[27] O. Ovcharuk, I. Ivaniuk, N. Soroko, O. Gritsenchuk, O. Kravchyna, E3S Web of Conferences 166 (2020)

[28] N. Soroko, CEUR Workshop Proceedings 2732, $1260(2020)$
[29] O. Yaroshenko, O. Samborska, A. Kiv, CEUR Workshop Proceedings 2643, 94 (2020)

[30] I. Trubavina, S. Dotsenko, O. Naboka, M. Chaikovskyi, H. Meshko, Journal of Physics: Conference Series 1840, 012052 (2021)

[31] IVET, Commission. survey results. entrepreneurship (2020), https://ivet.edu.ua/images/ activity/eksperymentalna-robota/zvity/ 2020_Komisiia_Rezultaty_opytuvannia_ Pidpryiemnytstvo.pdf

[32] Cabinet of Ministers of Ukraine, On the approval of the concept of the state target programme on the introduction of the one hundred percent information and communication technologies in the educational process of comprehensive schools for the period until 2015 (2014), https://zakon.rada. gov.ua/laws/show/1722-2010-p\#Text

[33] Prometheus, Entrepreneurship (2020), https:// prometheus.org.ua/cub/

[34] Ministry of Digital Transformation and YEP, Start a startup (2020), https: //osvita.diia.gov.ua/ courses/startuj-startap

[35] O. Romanska, Youth entrepreneurship - realities and prospects (2017), https: //cutt. ly/CzKL3EE

[36] O. Romanska, A useful textbook on creative entrepreneurship (2017), https: //cutt. 1y/ZzKZr3x

[37] H. Strykun, PRO effective regulation platform: a real help to entrepreneurs! (2017), https://cutt.ly/ SzKZaF1

[38] M. Doronina, V. Peresunko, Economics and Management 4, 7 (2016)

[39] S. Reznik, I. Chemezov, Nauk. 9 (2017)

[40] V.I. Dovhanets, Information Technologies and Learning Tools 78, 105 (2020) 